\title{
Exploration of Ruthenium (III) Chloride catalysis on oxidative conversion of aryloximes to arylaldehydes with bromamine-B: A kinetic and mechanistic approach
}

\author{
Manjunatha A $S^{1 *}$, Anu Sukhdev ${ }^{2}$, Puttaswamy ${ }^{3}$ and Shashidhara $T S^{4}$ \\ ${ }^{1}$ Department of Chemistry, Don Bosco Institute of Technology (Affiliated to Visvesvaraya Technological University - Belagavi) \\ Mysore Road, Bengaluru 560 074, India, \\ ${ }^{2}$ Department of Chemistry, Presidency University, Bengaluru-560 064, India \\ ${ }^{3}$ Department of Chemistry, Jnanabharati Campus, Bangalore University, Bangalore-560 056, India \\ ${ }^{4}$ Department of Physics, Siddaganga College of Arts, Science and Commerce, Tumakuru, 572102, India \\ *madhumanjuas@gmail.com
}

\begin{abstract}
Conversion of aryloximes to corresponding arylaldehydes is an important oxidative transformation in synthetic chemistry. In the course of this research, optimum conditions for the facile oxidation of benzaldehyde oxime and $p$-substituted benzaldehyde oximes viz., $p$ hydroxybenzaldehyde oxime, $p$-methoxybenzaldehyde oxime, $p$-bromobenzaldehyde oxime and $p$-nitrobenzaldehyde oxime (aryloximes) with bromamine-B (BAB) catalyzed by ruthenium (III) chloride $\left(\mathrm{RuCl}_{3}\right)$ in perchloric acid $\left(\mathrm{HClO}_{4}\right)$ medium have been kinetically investigated at 303 $\mathrm{K}$. All the five aryloximes follow identical kinetics with a first-order dependence of rate on $[\mathrm{BAB}]_{\mathrm{o}}$, fractional-order each on [aryloximes $]_{\mathrm{o}}$ and $\left[\mathrm{RuCl}_{3}\right]$, and an inverse fractional-order on $\left[\mathrm{H}^{+}\right]$. Activation parameters have been evaluated. Oxidation products were characterized by spectral analysis. Under the identical set of experimental conditions, the kinetics of catalyzed reactions has been compared with uncatalyzed reactions and found that the catalyzed reactions are 4-6 folds faster. Isokinetic temperature is found to be $338 \mathrm{~K}$. The catalytic constants (Kc) have been calculated at different temperatures and the values of activation parameters with respect to the catalyst have been evaluated. Spectroscopic evidence for the formation of 1:1 complex between $\mathrm{BAB}$ and $\mathrm{RuCl}_{3}$ has been obtained. The observed results have been explained by a plausible mechanism and the related rate law has been deduced. The present method offers many advantages including high conversion, short reaction times and the involvement of nontoxic reagents.
\end{abstract}

Key words: $\mathrm{RuCl}_{3}$-catalysis, Aryloximes, Arylaldehydes, Bromamine-B, Oxidation. 


\section{Introduction}

A convenient oxidative conversion of aryloximes to carbonyl compounds is an important reaction in both laboratory and industries. Oximes are highly crystalline compounds which serve as an efficient protecting group for carbonyl compounds and also for preparation, utilization for isolation, characterization and purification of carbonyl compounds [1]. Oxidation process plays a vital role in organic chemistry for the synthesis of industrial and pharmaceutical important organic molecules. Numerous methods are available for the synthesis and oxidation of organic molecules using different oxidants ranging from metal oxidants to atmospheric $\mathrm{O}_{2}$. However, still there is a need for developing eco-friendly methodologies and introduction of safe, costeffective and stable reagents for the synthesis of organic molecules via oxidation process. The development of new processes for the selective oxidations with eco-friendly oxidants has potential practical applications in organic synthesis. In this regard, a large group of compounds entitled sodium $N$-haloarenesulfonamidates (organic $N$-haloamines) are widely used in fine organic synthesis. Although aryloximes have been oxidized by variety of oxidants, a very few reports are available [2-5] from their kinetic and mechanistic standpoints. Hence, we felt it would be worthwhile to investigate the oxidative behavior of organic $N$-haloamines with aryloximes to explore the kinetic, mechanistic and catalytic aspects of these redox reactions.

The chemistry of organic $N$-haloamines has attracted the attention of many researchers on account of their miscellaneous behavior. The diverse nature of the chemistry of organic $\mathrm{N}$ haloamines is due to their ability to act both as bases and nucleophiles [6]. The leading members of this class of compounds are chloramine-T (CAT) and chloramine-B (CAB). The chemistry of these reagents has been well documented [7-10]. These reagents have been employed as oxidizing/chlorinating agents in the kinetic and mechanistic studies for oxidation of different functional groups. The bromine analogues of CAT and CAB are bromamine- $T$ $\left(\mathrm{C}_{6} \mathrm{H}_{4} \mathrm{SO}_{2} \mathrm{NBrNa} \cdot 3 \mathrm{H}_{2} \mathrm{O}\right.$ or BAT $)$ and bromamine- $\mathrm{B}\left(\mathrm{C}_{6} \mathrm{H}_{5} \mathrm{SO}_{2} \mathrm{NBrNa} 1.5 \mathrm{H}_{2} \mathrm{O}\right.$ or BAB$)$. These compounds can be easily prepared by the bromination of CAT and $\mathrm{CAB}$ and were found to be advanced oxidizing agents than the chloro compounds. Literature says that relatively less attention [11-13] was paid towards the kinetics and mechanism of oxidation of organic substrates involving BAT and BAB as oxidizing agents. Our preliminary kinetic runs assessment began 
with CAT and $\mathrm{CAB}$ as oxidants for the oxidative conversion of aryloximes in acid medium under diverse experimental conditions. The reactions were too lethargic to be measured kinetically. Then we consideration of using BAT and BAB as oxidants in acid medium and found that the reactions to be viable. $\mathrm{HClO}_{4}$ is used to provide acidic medium to the reaction mixture. However, the reaction was found to be more efficient with $\mathrm{BAB}$ in comparison with BAT, under similar experimental conditions. Hence, BAB have been selected as an oxidant for the oxidation of aryloximes in acid medium. However, the oxidation reaction is still sluggish to be measured kinetically in acid medium and hence it is necessary to employ few catalysts in the present study.

Transition metal ions as catalysts in many synthetic and redox reactions have become imperative in last few decades. The process of catalysis plays an important role in the production of chemicals and growth of chemical industries. Homogeneous catalysis is one of the most interesting fields of chemistry, especially for its mechanisms and kinetics. It provides admirable opportunity for the study of molecular causes of reactivity, of what makes reactions go. In recent years the use of transition metal ions such as $\mathrm{OsO}_{4}, \mathrm{RuCl}_{3}, \mathrm{PtCl}_{4}, \mathrm{PdCl}_{2}, \mathrm{RhCl}_{3}$ and $\mathrm{IrCl}_{3}$ as catalysts in redox reactions has gained importance, as these elements have strong catalytic influence in many industrial and biological processes. Transition metal ions have been employed as catalysts in the $N$-haloamine oxidation of a number of organic substrates [14-16] and some of these systems have proved suitable for kinetic analysis. Oxidizing and catalytic activities of transition metal ions are due to the existence of variable oxidation states, as a consequence of partially filled $\mathrm{d}$ or $\mathrm{f}$ orbitals. Their ability to form both $\sigma$ and $\pi$ bonds with other moieties or ligands is one of the chief facts for imparting catalytic properties to transition metals as well as their complexes. Most of the d-block elements show characteristic inter-ligand migration reactions and such a process forms one of the most important types of reactions in homogeneous catalysis. Our preliminary experimental results revealed that a micro quantity of ruthenium trichloride $\left(\mathrm{RuCl}_{3}\right)$ potentially catalyses the oxidation of selected aryloximes by $\mathrm{BAB}$ in acid medium. Inspired by recent findings, herein we report that a simple and efficient method to oxidized aryloximes to corresponding arylaldehydes under mild experimental conditions by using $\mathrm{BAB}$ as an oxidizing agent and $\mathrm{RuCl}_{3}$ as a catalyst. 
The main scientific novelty of the present study are to: (i) prepare BAB from CAB to explore its application as oxidant, (ii) develop an efficient synthetic process for the facile conversion of aryloximes to arylaldehydes, (iii) elucidate a plausible mechanism and to deduce an appropriate rate law, (iv) ascertain the various reactive species, (v) structure reactivity studies of aryloximes, (vi) find the catalytic efficiency of $\mathrm{RuCl}_{3}$ and to compare the reactivity with under uncatalyzed oxidation, and (vii) study the intermediate complex between $\mathrm{RuCl}_{3}$ and $\mathrm{BAB}$. The present method offers many advantages including high conversion, short reaction times and the involvement of non-toxic reagents.

\section{Materials and methods}

\section{Materials and methods}

Bromamine-B (BAB) was prepared and characterized known procedure [17] and the concentration of stock solution of BAB was periodically determined [18]. Benzaldehyde oxime and $p$-substituited benzaldehyde oximes were prepared by standard methods [19] and their melting points were checked with the literature values [20]. Aqueous solutions of aryloximes were prepared and employed. A stock solution of $\mathrm{RuCl}_{3}$ (Merck) was prepared by dissolving the sample in $20 \mathrm{mM} \mathrm{HCl}$. An allowance for $\mathrm{HCl}$ present was made in the catalyst solutions while preparing reaction mixtures for kinetic runs. Reagent grade chemicals and double distilled water were used throughout the research work.

The detailed kinetic experiments were made with respect to conversion of aryloximes to arylaldehydes with $\mathrm{BAB}$ as model reaction. The reactions were carried out under pseudo firstorder conditions with a known excess of [aryloximes] over [BAB] at $303 \mathrm{~K}$. The reactions were carried out in stoppered Pyrex boiling tubes whose outer surfaces were coated black to eliminate photochemical effects. For each run, requisite amounts of solutions of aryloximes, $\mathrm{HClO}_{4}$, $\mathrm{RuCl}_{3}$ and $\mathrm{BAB}$ (to keep the total volume constant for all runs) were introduced in to the tube and thermostated at 303K until thermal equilibrium was attained. A Raaga ultra cold chamber with digital temperature control (Chennai, India) was used to maintain the desired temperature constant with an accuracy of $\pm 0.1^{\circ} \mathrm{C}$. A measured amount of $\mathrm{BAB}$ was rapidly added with stirring to the mixture in the tube. The progress of the reaction was monitored by the iodometric determination of unreacted $\mathrm{BAB}$ in aliquots $(5 \mathrm{~mL}$ each) of the reaction mixture withdrawn at different intervals of time. The course of the reaction was studied for at least two half-lives. The 
pseudo first-order rate constants $\left(k^{\prime}\right)$ calculated from the linear plots of log [aryloximes] versus time were reproducible within $\pm 4 \%$. Regression coefficients $\left(\mathrm{R}^{2}\right)$ for all the linear plots were calculated using origin pro 8.5 software.

\section{Reaction stoichiometry and product analysis}

Reaction mixtures containing different ratios of $\mathrm{BAB}$ to aryloximes in the presence of $1.6 \times 10^{-4}$ mol dm${ }^{-3} \mathrm{HClO}_{4}$ and $16.0 \times 10^{-6} \mathrm{RuCl}_{3}$ were equilibrated at $303 \mathrm{~K}$ for $24 \mathrm{~h}$. Determination of unreacted $\mathrm{BAB}$ in reaction mixture showed that one mole of aryloximes consumed one mole of $\mathrm{BAB}$, confirming by the following reaction stoichiometry Eq. (1).

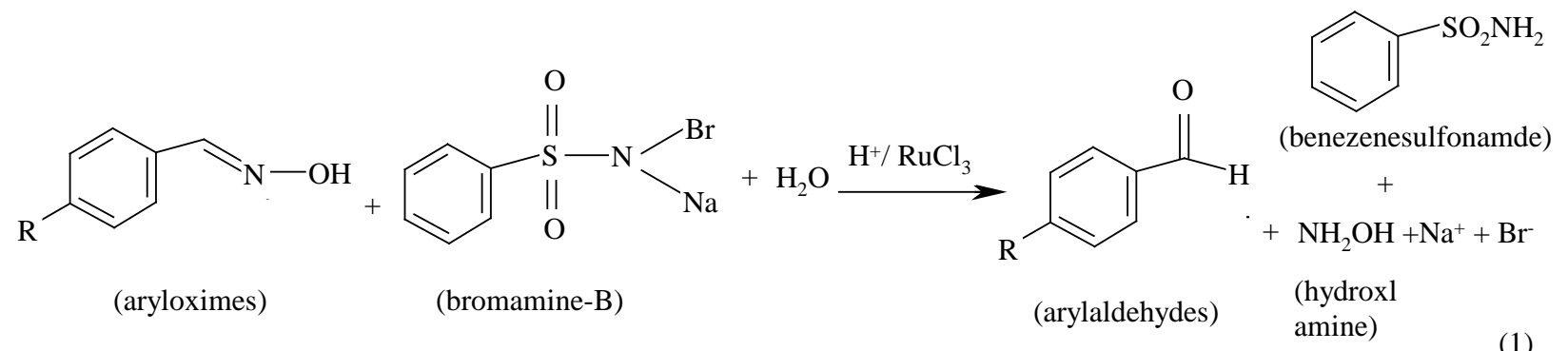

Here $\mathrm{R}=-\mathrm{OH}$ for $p$-hydroxybenzaldehyde oxime, $-\mathrm{OCH}_{3}$ for $p$-methoxybenzaldehyde oxime, $-\mathrm{H}$ for benzaldehyde oxime, $-\mathrm{Br}$ for $p$-bromobenzaldehyde oxime and $-\mathrm{NO}_{2}$ for $p$-nitro benzaldehyde oxime.

In a round bottomed flask, aryloximes $(1 \mathrm{mmol})$, bromamine- $\mathrm{B}(2 \mathrm{mmol})$ were dissolved in water. The reactions were initiated by adding $0.2 \mathrm{mmol}$ of $\mathrm{RuCl}_{3}$ catalyst and the mixtures were stirred at $303 \mathrm{~K}$ for $6 \mathrm{~h}$ in presence of $\mathrm{HClO}_{4}$. After completion of the reaction (monitored by TLC), the reaction products were neutralized with base and extracted with ether. The organic products were subjected to spot tests and chromatographic analysis. Further, the reaction mixture was extracted with ethyl acetate and dried over $\mathrm{Na}_{2} \mathrm{SO}_{4}$. The solvent was evaporated under reduced pressure to obtain crude products. The crude products were purified on silica gel column by using petroleum ether and ethyl acetate as solvent to get the pure products. Above analysis revealed the formation of corresponding arylaldehydes as the oxidation products of aryloximes. $p$-hydroxybenzaldehyde, $p$-methoxybenzaldehyde, benzaldehyde, $p$-bromobenzaldehyde and $p$ nitrobenzaldehyde (arylaldehydes) are the oxidation products of $p$-hydroxybenzaldehyde oxime, $p$-methoxybenzaldehyde oxime, benzaldehyde oxime, $p$-bromobenzaldehyde oxime and $p$ - 
nitrobenzaldehyde oxime respectively. Further, $p$-hydroxybenzaldehyde, $p$-bromobenzaldehyde, benzaldehyde and p-nitrobenzaldehyde were confirmed by NMR spectral studies. The quantitative characteristic of the ${ }^{1} \mathrm{H}$ NMR spectra are; p-hydroxy benzaldehyde; $\delta=10.15$ (s, 1H), $8.40-8.38$ (d, 2H), $8.08-8.06(\mathrm{~d}, 2 \mathrm{H}), 5.57$ (s, 1H): p-bromo benzaldehyde; $\delta=9.98$ (s, 1H), 7.76-7.68 (m, 4H): benzaldehyde;); $\delta=10.0$ (s, 1H), $7.90-7.40$ (m, 5H): p-nitro benzaldehyde; $\delta=9.86$ (s, 1H), $7.83-7.81$ (d, 2H), $7.00-6.97$ (d, 2H). NMR spectra were obtained on a Bruker WH 400-MHz Nuclear Magnetic Resonance Spectrometer. Further, no reaction was noticed between all these five oxidation products with $\mathrm{BAB}$ under the present set of experimental conditions. Furthermore, we have succeeded in estimating the products, arylaldehydes, in case of all the five aryloximes. The reaction times and yields are given in Table 1. These products were identified by TLC, boiling points and melting points by comparison with authentic samples. Benzenesulfonamide, a reduction product of $B A B$, was also extracted with ethyl acetate and identified [22] by TLC using petroleum ether- $\mathrm{CHCl}_{3}-1$-butanol (2:2:1, v/v) as a solvent system and iodine as a spray reagent $\left(\mathrm{R}_{\mathrm{f}}=0.88\right)$.

\section{Results and discussion}

Kinetic orders: The oxidation-kinetics of five oximes viz., $p$-hydroxybenzaldehyde oxime, $p$ methoxybenzaldehyde oxime, benzaldehyde oxime, $p$-bromobenzaldehyde oxime and $p$ nitrobenzaldehyde oxime (aryloximes) by $\mathrm{BAB}$ have been investigated at several initial concentrations of the reactants in the presence of $\mathrm{HClO}_{4}$ and $\mathrm{RuCl}_{3}$ catalyst at $303 \mathrm{~K}$. Under pseudo-first-order conditions of [aryloximes $]_{0} \gg[\mathrm{BAB}]_{\mathrm{o}}$ at constant $\left[\mathrm{HClO}_{4}\right],\left[\mathrm{RuCl}_{3}\right]$ and temperature, plots of $\log [\mathrm{BAB}]$ versus time were linear $\left(\mathrm{R}^{2}>0.9925\right)$, indicating a first-order dependence of rate on $[\mathrm{BAB}]_{\mathrm{o}}$. The linearity of these plots, together with the constancy of the slopes obtained at various [BAB] confirming the first-order dependence on [BAB] (Table 2). Under the similar experimental conditions, an increase in [aryloximes] increased the $\mathrm{k}^{\prime}$ values (Table 1). Plots of $\log \mathrm{k}^{\prime}$ versus $\log$ [aryloximes] o were linear $\left(\mathrm{R}^{2}>0.9989\right)$ with fractionalslopes $(0.66-0.80)$, showing a fractional-order dependence of rate on [aryloximes] $]_{0}$. Further, plots of $\mathrm{k}^{\prime}$ versus [aryloximes] were linear $\left(\mathrm{R}^{2}=0.9954\right)$ having an y-intercept, confirming the fractional-order dependence on [aryloximes] . $_{\text {. }}$

The rate increased with decrease in $\left[\mathrm{HClO}_{4}\right]$ (Table 3) and plots of log $\mathrm{k}^{\prime}$ versus $\log \left[\mathrm{HClO}_{4}\right]$ were linear $\left(R^{2}>0.9982\right)$ with negative fractional slopes $(-0.43$ to -0.53$)$, showing a negative fractional-order dependence of the rate on $\left[\mathrm{HClO}_{4}\right]$. The reaction rate increased with increase in 
$\left[\mathrm{RuCl}_{3}\right]$ (Table 3) and plots of $\log \mathrm{k}^{\prime}$ versus $\log \left[\mathrm{RuCl}_{3}\right]$ were linear $\left(\mathrm{R}^{2}>0.9961\right)$ with fractional slopes (0.41 - 0.78), confirming fractional-order dependence on $\left[\mathrm{RuCl}_{3}\right]$. Similarly, the effect of initially added benzenesulfonamide (BSA or $\mathrm{PhSO}_{2} \mathrm{NH}_{2}$ ) on the rate of reaction was studied in presence of $8.0 \times 10^{-4} \mathrm{~mol} \mathrm{dm}^{-3} \mathrm{BSA}$. No significant effect of BSA on the rate of the reaction was noticed. This implies that BSA is not involved in any step prior to the rate determining step (rds). No attempt has been made to keep the ionic strength of the medium constant, since the rate remains unaltered in the presence of $0.3 \mathrm{~mol} \mathrm{dm}^{-3} \mathrm{NaClO}_{4}$ solution. The effect of $\mathrm{Br}^{-}$ion was studied using $4.0 \times 10^{-3} \mathrm{~mol} \mathrm{dm}^{-3} \mathrm{NaBr}$ solution. There was no change in the pseudo-first-order rate constant, suggesting that no free bromine is formed in the reaction sequence.

Effect of varying temperature on the rate and free radical test: The reaction rates were determined at different temperatures and based on the Arrehenius plots of log $k^{\prime}$ versus $1 / T\left(R^{2}>\right.$ 0.9918), values of activation parameters were evaluated and tabulated in Table 4 . The possibility of the formation of free radicals was examined by adding $10 \%(\mathrm{v} / \mathrm{v})$ acrylonitrile to the partially oxidized reaction mixture. No precipitation was observed after a long time, which indicated the absence of free radical intervention. The control experiments were also performed under similar reaction conditions without the oxidant.

Reactive species of BAB: The behavior of $\mathrm{BAB}$ is analogous to that of $\mathrm{CAT}$ and $\mathrm{CAB}$, and it behaves like a strong electrolyte in both acidic and alkaline media forming different species depending on $\mathrm{pH}$ of the medium [23]. The oxidation potential of $\mathrm{BAB} / \mathrm{PhSO}_{2} \mathrm{NH}_{2}$ is $\mathrm{pH}$ dependent [24] and decreases with an increase in $\mathrm{pH}$ of the medium (1.4 $\mathrm{V}$ at $\mathrm{pH} 0.65$ and 0.50 $\mathrm{V}$ at $\mathrm{pH}$ 12.0). The possible oxidizing species in acid solutions of $\mathrm{BAB}$ are $\mathrm{PhSO}_{2} \mathrm{NHBr}$, $\mathrm{PhSO}_{2} \mathrm{NBr}_{2}, \mathrm{HOBr}$ and perhaps $\mathrm{H}_{2} \mathrm{O}^{+} \mathrm{Br}$ and in alkaline $\mathrm{BAB}$ solutions they are $\mathrm{PhSO}_{2} \mathrm{NHBr}$, $\mathrm{PhSO}_{2} \mathrm{~N}^{-} \mathrm{Br}, \mathrm{HOBr}$ and $\mathrm{O}^{-} \mathrm{Br}$ [18, 23-25]. If $\mathrm{HOBr}$ is the active species, then a first-order retardation of rate by the added benzenesulfonamide $\left(\mathrm{PhSO}_{2} \mathrm{NH}_{2}\right)$ should be observed. Absence of a retardation effect by the added $\mathrm{PhSO}_{2} \mathrm{NH}_{2}$ rules out the involvement of $\mathrm{HOBr}$ in the reaction sequence. Further, if $\mathrm{PhSO}_{2} \mathrm{NBr}_{2}$ were to be the reactive species, then the rate law predicts a second-order dependence of rate on $[\mathrm{BAB}]$, but experimentally first-order plots were obtained for the disappearance of $\mathrm{BAB}$ and hence $\mathrm{PhSO}_{2} \mathrm{NBr}_{2}$ can be ruled out as the oxidizing species. Further, Soper [26] reported that $[\mathrm{HOCl}]$ is very small and is independent of [CAT], also, the predominant species of CAT is TsNHCl under acidic conditions. Narayanan and Rao [27] and 
Subhashini et al [28] have reported that TsNHCl can further be protonated as $\mathrm{TsN}^{+} \mathrm{H}_{2} \mathrm{Cl}$. Since haloamines have similar chemical properties, the same argument holds good for BAB also. In the present case an inverse fractional dependence on $\left[\mathrm{H}^{+}\right]$suggests that deprotonation of $\mathrm{PhSO}_{2} \mathrm{~N}^{+} \mathrm{H}_{2} \mathrm{Br}$ results in the formation of $\mathrm{PhSO}_{2} \mathrm{NHBr}$, which is likely to be the active oxidizing species involved in the oxidation of aryloximes in acid medium.

Reactive Species of $\mathbf{R u C l}_{3}$ : The use of $\mathrm{RuCl}_{3}$ as a homogeneous catalyst in both acidic and alkaline media is of current interest. The mechanism of catalysis is quite complicated due to the formation of different intermediate complexes, free radicals and different oxidizing states of $\mathrm{RuCl}_{3}$. Cady and Connick [29] and Connick and Fine [30] have investigated aqueous $\mathrm{RuCl}_{3}$ complex species using the ion exchange resins and UV-spectral studies. They found that the octahedral complex species $\left[\mathrm{RuCl}_{5}\left(\mathrm{H}_{2} \mathrm{O}\right)\right]^{2-},\left[\mathrm{RuCl}_{4}\left(\mathrm{H}_{2} \mathrm{O}\right)_{2}\right]^{-},\left[\mathrm{RuCl}_{3}\left(\mathrm{H}_{2} \mathrm{O}\right)_{3}\right],\left[\mathrm{RuCl}_{2}\left(\mathrm{H}_{2} \mathrm{O}\right)_{4}\right]^{+}$ and $\left[\mathrm{RuCl}\left(\mathrm{H}_{2} \mathrm{O}\right)_{5}\right]^{2+}$ may not exist in aqueous solution of $\mathrm{RuCl}_{3}$. Other studies [31-33] have shown in acidic solutions the following equations exist for $\mathrm{RuCl}_{3}$ :

$\mathrm{RuCl}_{3} \mathrm{xH}_{2} \mathrm{O}+3 \mathrm{HCl} \longrightarrow\left[\mathrm{RuCl}_{6}\right]^{3-}+\mathrm{xH}_{2} \mathrm{O}+3 \mathrm{H}^{+}$

$\left[\mathrm{RuCl}_{6}\right]^{3-}+\mathrm{H}_{2} \mathrm{O} \rightleftharpoons\left[\mathrm{RuCl}_{5}\left(\mathrm{H}_{2} \mathrm{O}\right)\right]^{2-}+\mathrm{Cl}^{-}$

In the present study, the absence of chloride ion on the rate indicates that the equilibrium (3) does not play any role in the reaction and hence the complex ion, $\left[\mathrm{RuCl}_{5}\left(\mathrm{H}_{2} \mathrm{O}\right)\right]^{2-}$, is assumed to be the reactive catalyst species.

Based on the aforesaid discussion and the experimental kinetic results, the general mechanism (Scheme 1) has been proposed for the $\mathrm{RuCl}_{3}$ catalyzed oxidation of aryloximes to arylaldehydes using $\mathrm{BAB}$ in $\mathrm{HClO}_{4}$ medium.

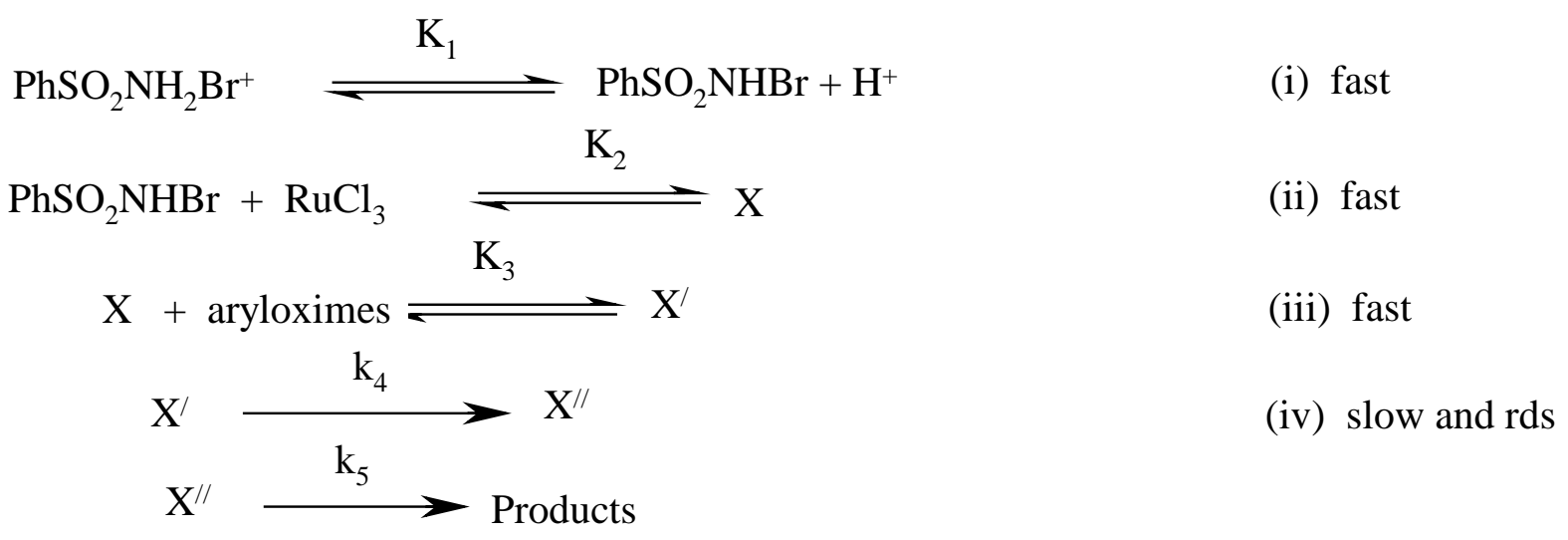


Scheme 1. A general reaction scheme for $\mathrm{RuCl}_{3}$ catalyzed oxidative conversion of aryloximes with $\mathrm{BAB}$ in $\mathrm{HClO}_{4}$ medium.

The probable mode of this reaction scheme and structure of the complex intermediate species $\mathrm{X}$, $\mathrm{X}^{\prime}$ and $\mathrm{X}^{\prime \prime}$ are depicted in Scheme 2. Under optimum experimental reaction conditions, evidence for the formation of complex between $\mathrm{BAB}$ and $\mathrm{RuCl}_{3}$ is obtained from the UV-Visible spectra of $\mathrm{BAB}, \mathrm{RuCl}_{3}$ and the mixture of both. Absorption maxima appear at 226nm for $\mathrm{BAB}, 218 \mathrm{~nm}$ for $\mathrm{RuCl}_{3}$ in aqueous acidic medium, and $235 \mathrm{~nm}$ for their mixture. A bathochromic shift of 17 $\mathrm{nm}$ from 218 to $235 \mathrm{~nm}$ of $\mathrm{RuCl}_{3}$ suggests that complexation occurs between $\mathrm{BAB}$ and $\mathrm{RuCl}_{3}$ in the present case (Fig. 1).

In Scheme 2, in an initial equilibrium [step (i)], deprotonation of $\mathrm{PhSO}_{2} \mathrm{~N}^{+} \mathrm{H}_{2} \mathrm{Br}$ generates the conjugate free acid $\mathrm{PhSO}_{2} \mathrm{NHBr}$. In the next fast pre-equilibrium [step (ii)], the donor nitrogen atom of the oxidizing species co-ordinates to the metal centre of the active catalyst species and gives an intermediate complex $\mathrm{X}$. This intermediate complex $\mathrm{X}$ in the next fast step [step (iii)], forms another intermediate complex $\mathrm{X}^{\prime}$ with the substrate. In slow / rds [step (iv)], $\mathrm{X}^{\prime}$ disproportionates to form another intermediate species $\mathrm{X}^{\prime \prime}$ with the regeneration of the catalyst species and elimination of $\mathrm{PhSO}_{2} \mathrm{NH}_{2}$. Finally, this intermediate complex $\mathrm{X}^{\prime \prime}$ undergoes hydrolysis in a fast step to give the ultimate products (arylaldehydes), with the elimination of $\mathrm{HBr}$ and hydroxylamine. The probable structure of the complex $\mathrm{X}$ is:

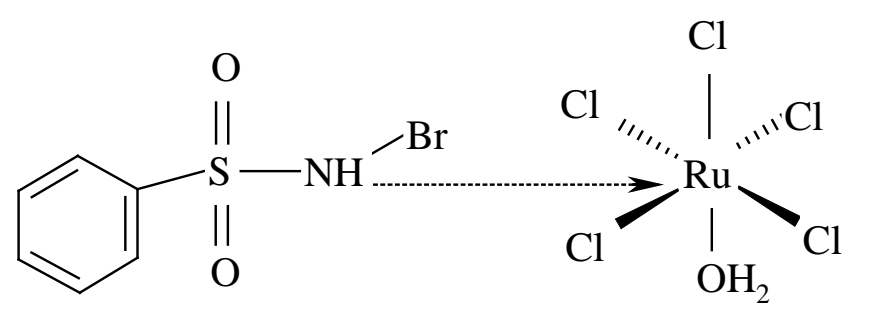

If $[\mathrm{BAB}]_{\mathrm{t}}$ is the total effective concentration of $\mathrm{BAB}$, then

$[\mathrm{BAB}]_{\mathrm{t}}=\left[\mathrm{PhSO}_{2} \mathrm{~N}^{+} \mathrm{H}_{2} \mathrm{Br}\right]+\left[\mathrm{PhSO}_{2} \mathrm{NHBr}\right]+[\mathrm{X}]+\left[\mathrm{X}^{\prime}\right]$

From steps (i), (ii) and (iii) of Scheme 1, 
$\left[\mathrm{PhSO}_{2} \mathrm{NH}_{2} \mathrm{Br}^{+}\right]=\frac{\left[\mathrm{X}^{\prime}\right]\left[\mathrm{H}^{+}\right]}{\mathrm{K}_{1} \mathrm{~K}_{2} \mathrm{~K}_{3} \text { [aryloximes] }\left[\mathrm{RuCl}_{3}\right]}$

$\left[\mathrm{PhSO}_{2} \mathrm{NHBr}\right]=\frac{\left[\mathrm{X}^{\prime}\right]}{\mathrm{K}_{2} \mathrm{~K}_{3} \text { [aryloximes] }\left[\mathrm{RuCl}_{3}\right]}$

$[\mathrm{X}]=\frac{\left[\mathrm{X}^{\prime}\right]}{\mathrm{K}_{3} \text { [aryloximes] }}$

By substituting for $\left[\mathrm{PhSO}_{2} \mathrm{NH}_{2} \mathrm{Br}^{+}\right]$, [ $\left.\mathrm{PhSO}_{2} \mathrm{NH}_{2} \mathrm{Br}\right]$ and [X] from Eqs. (5), (6) and (7) into Eq. (4) and solving for $\left[\mathrm{X}^{\prime}\right]$, one obtains

$\left[\mathrm{X}^{\prime}\right]=\frac{\mathrm{K}_{1} \mathrm{~K}_{2} \mathrm{~K}_{3}[\mathrm{BAB}]_{\mathrm{t}} \text { [aryloximes] }\left[\mathrm{RuCl}_{3}\right]}{\left.\left[\mathrm{H}^{+}\right]+\mathrm{K}_{1}+\mathrm{K}_{1} \mathrm{~K}_{2}\left[\mathrm{RuCl}_{3}\right]+\mathrm{K}_{1} \mathrm{~K}_{2} \mathrm{~K}_{3} \text { [aryloximes }\right]\left[\mathrm{RuCl}_{3}\right]}$

From the slow and rds of Scheme 1,

Rate $=-\mathrm{d}[\mathrm{BAB}]_{\mathrm{t}} / \mathrm{dt}=\mathrm{k}_{4}\left[\mathrm{X}^{\prime}\right]$

By substituting for $\left[\mathrm{X}^{\prime}\right]$ from Eq. (8) into Eq. (9), the following rate law is obtained:

$$
-\mathrm{d}[\mathrm{BAB}] / \mathrm{dt}=\frac{\mathrm{K}_{1} \mathrm{~K}_{2} \mathrm{~K}_{3} \mathrm{k}_{4}[\mathrm{BAB}]_{\mathrm{t}} \text { [aryloximes] }\left[\mathrm{RuCl}_{3}\right]}{\left[\mathrm{H}^{+}\right]+\mathrm{K}_{1}+\mathrm{K}_{1} \mathrm{~K}_{2}\left[\mathrm{RuCl}_{3}\right]+\mathrm{K}_{1} \mathrm{~K}_{2} \mathrm{~K}_{3} \text { [aryloximes] }\left[\mathrm{RuCl}_{3}\right]}
$$

Rate law (10) is in good agreement with the experimental results. The proposed Scheme and the derived rate law are also substantiated by the experimental observations discussed below.

The proposed reaction mechanism is also evinced by the observed zero effect of ionic strength on the rate of the reaction. In the present case, variation of ionic strength of the medium does not alter the rate of reaction, clearly signifies that one of the reactant species is a neutral molecule as can be seen in slow/rds of Scheme 1. Hence, the observed ionic strength effect is in agreement with the Bronsted and Bjerrum theory [34].

According to rate constants reported in Table 4, it can be seen that oxidation of $\mathrm{RuCl}_{3}$ catalyzed reaction is four to five fold faster than the without catalyst. The rate of oxidation of aryloximes by $\mathrm{BAB}$ in presence of $\mathrm{HClO}_{4}$ and $\mathrm{RuCl}_{3}$ catalyst increases in the order: $p$-hydroxybenzaldehyde oxime $>p$-methoxybenzaldehyde oxime $>$ benzaldehyde oxime $>p$-bromobenzaldehyde oxime $>p$-nitrobenzaldehyde oxime. This trend may be due to combined effect of the electronic and steric factors of the substitutents attached to the 4- position of benzene ring. The higher reactivity 
of $p$-hydroxybenzaldehyde oxime in comparison with $p$-methoxybenzaldehyde oxime can be legitimated due to the differences in the electron donating effect of the $-\mathrm{OH}$ and $-\mathrm{OCH}_{3}$ groups and also through the positive inductive effect, thereby enhancing the electron density by benzene ring make the reaction very fast. Furthermore, $p$-nitrobenzaldehyde oxime has least reactive assessment with $p$-bromobenzaldehyde oxime because the attached electron withdrawing group in $p$-nitrobenzaldehyde oxime rapidly decreases the nucleophilicity on the aromatic ring than electron withdrawing group present in p-bromobenzaldehyde oxime. It is clearly confirmed that increased order of the reaction is: $p$-hydroxybenzaldehyde oxime $>p$-methoxybenzaldehyde oxime $>$ benzaldehyde oxime $>p$-bromobenzaldehyde oxime $>p$-nitrobenzaldehyde oxime.

Activation parameters in presence of $\mathbf{R u C l}_{3}$ : It was felt necessary reasonable to compare the reactivity of $\mathrm{BAB}$ towards aryloximes in the absence of $\mathrm{RuCl}_{3}$ under similar set of experimental conditions in order to evaluate the catalytic efficiency of $\mathrm{RuCl}_{3}$. The reactions were studied at different temperatures (293-313 K) in absence of $\mathrm{RuCl}_{3}$. From the plots of $\log \mathrm{k}^{\prime}$ versus $1 / \mathrm{T}\left(\mathrm{R}^{2}\right.$ $>0.9902$ ), we evaluated the activation parameters for the uncatalyzed reactions (Table 4). The $\mathrm{RuCl}_{3}$ catalyzed reactions were found to be 4-6 fold faster and thus the observed results justify the need of a catalyst for a facile conversion of aryloximes by the chosen BAB in acid medium. The catalyst $\mathrm{RuCl}_{3}$ forms a complex with BAB, which increases the oxidizing property of chosen $\mathrm{BAB}$ than without catalyst.

Correlation analysis of reactivity: Structure reactivity is the manner in which the reactivity of the molecule changes when substituents are present and they are changed [35]. In order to probe the mechanism of a reaction using substituent effect, one has to study a different reactant in which a substituent has been added or changed. Substituent effects are used to determine how the free energies of the reaction and activation energy vary as a function of chemical structure in either kinetic or thermodynamic analysis. Structural modification on the reactant molecule may influence the rate or equilibrium constant of a reaction. Hammett linear free energy relationship (LFER) [36] describes the correlation between structure and reactivity. In the present case, attempts were made to correlate rates of oxidation of aryloximes with substituent constants $(\sigma)$. A fairly good correlation between $\log k^{\prime}$ versus $\sigma$ with a slope of -0.36 (Fig. 2; $\mathrm{R}^{2}=0.9987$ ) was observed, which is the reaction constant $(\rho)$. The negative sign of $\rho$ signifies that electron 
donating substitutents (-OH and $\left.-\mathrm{OCH}_{3}\right)$ accelerates the reaction rates and electron withdrawing substitutents $\left(-\mathrm{Br}\right.$ and $\left.-\mathrm{NO}_{2}\right)$ retards them, conforms to the Hammett LFER.

Isokinetic relationship: The isokinetic relationship is an important tool for deciding the nature of a mechanism. A correlation between enthalpy and entropy has been observed for a wide variety of reactions. LFERs are empirical relationships between thermodynamic quantities [37]. Isokinetic relationship is a linear relationship between enthalpy and entropy contributions which implies that the change in enthalpy in proceeding from a reaction or to a reaction in a series accompanied by a parallel change in enthalpy. Variation in rate within a reaction series may be caused by changes in either or both the enthalpy and the entropy of activation. Four categories can be recognized here and they are: i) Changes in rate are caused chiefly by changes in $\Delta \mathrm{H}^{\neq}$ when $\Delta S^{\neq}$is substantially constant. Many reaction series that follow the Hammett $\rho \sigma$ relationship fall within this category; ii) Changes in rate are caused primarily by changes in $\Delta \mathrm{S}^{\neq}$, when $\Delta \mathrm{H}^{\ddagger}$ is substantially constant; iii) Changes in rate are caused by random changes in both $\Delta \mathrm{H}^{\neq}$and $\Delta \mathrm{S}^{\neq}$; and iv) Changes in rate are caused by changes in both $\Delta \mathrm{H}^{\neq}$and $\Delta \mathrm{S}^{\neq}$, but these quantities vary in a parallel fashion. In the last category, $\Delta \mathrm{H}^{\ddagger}$ and $\Delta \mathrm{S}^{\neq}$are correlated by a linear relationship:

$\Delta \mathrm{H}^{\neq}=\Delta \mathrm{H}^{\neq}{ }_{0}+\beta \Delta \mathrm{S}^{\neq}$

Equation (11) is called the isokinetic relationship and here $\beta$ is the isokinetic temperature. Using the relation: $\Delta \mathrm{G}^{\neq}=\Delta \mathrm{H}^{\neq}-\mathrm{T} \Delta \mathrm{S}^{\neq}$, it can be shown that, $\delta \Delta \mathrm{G}^{\neq}=(1-\mathrm{T} / \beta) \delta \Delta \mathrm{S}^{\neq}$, where $\mathrm{T}$ is the experimental temperature. When $\beta=\mathrm{T}, \Delta \mathrm{G}^{\neq}=0$, and no variation of equilibrium or rate can be expected when substituent's or media are changed. All members of a series will then react at the same rate. When $\mathrm{T}<\beta$, the reaction rate or equilibrium is mainly by the enthalpy change. In this region, the reaction with the lowest activation energy will react fastest and interpretation involving potential energy surface can be made. This is very common case. At temperatures above $\beta$, however, the controlling factor is $\delta \Delta \mathrm{S}^{\neq}$and interpretations based upon potential energy surfaces would obviously be in error. In general, it is found that electronic effects are contained in the enthalpy factor and that many solvent effects are due to the entropy factor.

In the present study, rate constants and activation energies are tabulated in Table 4 revealed that activation energy is highest for the slowest reaction and vice-versa as expected, indicating that the reaction is under enthalpy controlled. This is verified by calculating the 
isokinetic temperature ( $\beta$ ) from the slope of the linear plot of $\Delta \mathrm{H}^{\ddagger}$ versus $\Delta \mathrm{S}^{\ddagger}\left(\mathrm{R}^{2}=0.9987\right)$. The value $\beta$ found is $331 \mathrm{~K}$, which is higher than the experimental temperature (303 K) employed in the present work. The genuine nature of isokinetic relationship was also tested through the Exner criterion [37] by plotting $\log k_{(303 \mathrm{~K})}^{\prime}$ versus $\log k_{(293 \mathrm{~K})}^{\prime}\left(\right.$ Fig. 3; $\left.\mathrm{R}^{2}=0.9993\right)$. The isokinetic temperature $\beta$ can be evaluated from the expression: $\beta=T_{1} T_{2}(b-1) / b T_{2}-T_{1}$ where $b$ is the slope of the Exner plot and $\beta$ was found to be $338 \mathrm{~K}$. The proposed mechanism is also supported by the moderate values of energy of activation and other activation parameters. The fairly high negative $\Delta S^{\neq}$values reflect a greater degree of ordering in the transition state than the initial state, due to an increase in solvation during the solvation process. An almost identical value of $\Delta \mathrm{G}^{\neq}$indicates the operation of a common mechanism for all the five aryloximes studied.

\section{Conclusion}

A simple and efficient method for the oxidative conversion of aryloximes to arylaldehydes was developed. All the five oxidation reactions followed identical kinetics and mechanism. Activation parameters and isokinetic temperature were deduced. The rate satisfactorily correlates with Hammett relationship. The rate of oxidation of aryloximes follows the trend: $p$ hydroxybenzaldehyde oxime $>p$-methoxybenzaldehyde oxime $>$ benzaldehyde oxime $>p$ bromobenzaldehyde oxime $>p$-nitrobenzaldehyde oxime. The observed results have been explained by a plausible mechanism and the related rate law has been deduced. The present method offers several advantages including good yield, short reaction time and stable, costeffective and involvement of relatively non-toxic reagents which make the reaction process simple and smooth. Hence, this method has great prospects in industrial applications.

\section{Acknowledgements}

Author ASM thanks the Executive Director, Principal and Management of Donbosco Institute of Technology for their motivation and support. 


\section{References}

1) Larock, R.C. Comprehensive Organic Transformations, Wiley-VCH, New York, 1999.

2) Mai K.; Patil, G. Synthesis. 1986, 12, 1037. DOI:

3) Kim, S.; Yi, K.Y. Tetrahedron Lett. 1986, 27, 1925.DOI: 10.1016/S0040-4020(01)86905-2.

4) Lingaiah, N.; Narender, R. Synth. Commun. 2002, 32, 2391. DOI:10.1081/SCC-120006011.

5) Kiasat, A.R.; Kazemi, F.; Khosravian, F. Phosp. Sul. Sil. Relat. Elem. 2003, 178, 1377. DOI: 10.3329/sja.v13i1.24176.

6) Campbell, M.M.; Johnson, G. Chem. Rev. 1978, 78, 65. DOI: 10.1021/cr60311a005

7) Banerji, K.K.; Jayaram, B.; Mahadevappa, D.S. J. Sci. Ind. Res. 1987, 46, 65.

8) Agnihotri, G. Synlett. 2005, 18, 2857. DOI: 10.1055/s-2055-918936.

9) Kolaveri, E.; Ghorbeni-Choghamarani, A.; Salehi, P.; Shirini, F.; Zolfigol, M.A. J. Iran. Chem. Soc. 2007, 4, 126. DOI: 10.1007/BF03245963.

10) Jagadeesh, R.V.; Puttaswamy. Encyclopedia of reagents for organic synthesis ChloramineT: second update, RC056, 9. 2013.

11) Ramya R.; Puttaswamy. Catal. Lett. 2017, 147, 1392.DOI: 10.1007/s10562-017-2034-4

12) Manjunatha, A.S.; Anu Sukhdev.; Puttaswamy. Russ. J. Phys. Chem. A 2018, 92(13) 47. DO10.1134/S0036024418130290

13) Dakshayani, S.; Puttaswamy. Catal Lett. 2018, 148(1), 424. DOI: 10.1007/s10562-0172244-9

14) Griffith, W.P. The Chemistry of Rare Platinum Metals. Interscience, New York, 1967.

15) Cotton, F.A.; Wilkinson, G.; Murillo, C.A.; Bochmann, M. Advanced Inorganic Chemistry, $6^{\text {th }}$ Edn, John wiley and Sons, New York, 1999.

16) Mallesh, R.T.; Bellakki, M.B.; Nandibewoor, S.T. Catal. Lett. 2004, 97, 91. DOI: 10.1023/B:CATL.0000034293.78427.8d

17) Mahadevappa, D.S.; Ahmed, M.S. Talanta, 1979, 26(7), 590. DOI: 10.1016/00399140(79)80097-1

18) Morris, J.C.; Salazar, J.A.; Wineman, M.A. J. Am. Chem. Soc. 1948, 70, 2036. DOI: 10.1021/ja01186a016

19) Ahluwalia, V.K.; Dhingra, S. In Comprehensive Practical Organic Chemistry, Qualitative Analysis, University Press, Hyderabad, 2000.

20) Lakhinath, S.; Jejiron, M.; Baruah, J.T. Org. Med. Chem. Lett. 2011, 1, 12. 
DOI:10.1002/jccs.201200011

21) Jagadeesh, R.V.; Puttaswamy. J. Phys. Org. Chem. 2008, 21(10), 844. DOI: 10.1002/poc.1379

22) Venkatesha, B.M.; Ananda,S.; Mahadevappa, D.S. J. Phys. Org. Chem. 1992, 5, 373.DOI: 10.1002/poc.610050702

23) Bishop, E.; Jennings, V.J. Talanta, 1958, 10, 197. DOI: 10.1016/0039- 9140(58)80034-X

24) Murthy, A.R.V.; Rao, B.S. Proc. Ind. Acad. Sci. 1952, 36, 425. DOI: 10.1007/BF03172242.

25) Hardy, F.F.; Johnston, J.P. J. Chem. Soc. Perkin. Trans. II. 1973, 742.

26) Soper, F.G. J. Chem. Soc. 1942, 1899.

27) Narayanan, S.S.; Rao, V.R.S. Radiochem. Acta. 1983, 32, 211.DOI: 10.1524/ract.1983.32.4.211

28) Subhashini, M.; Subramanian, M.; Rao, V.R.S. Talanta, 1985, 32, 1082.DOI: 10.1016/0039-9140(85)80130-2

29) Cady, H.H.; Connick, R.E. J. Am. Chem. Soc. 1958, 80, 2646.

30) Connick, R.E.; Fine, D.A. . J. Am. Chem. Soc. 1960, 82, 4187.DOI: 10.1021/ja01501a018

31) Griffith, W.P. The Chemistry of Rare Platinum Metals, Interscience, New York, 1967.

32) Backhouse, J.R.; Dwyer, F.D.; Shales, N. Proc. Roy. Soc. 1950, 83, 146.

33) Davfokratova, T. Analytical Chemistry of Ruthenium. Academy of Sciences, USSR, 1963.

34) Laidler, K.J. Chemical Kinetics, $3^{\text {rd }}$ Edn, Pearson education, South Asia, 2012.

35) Eric, V.A.; Dennis, D.A. Modern Physical Organic Chemistry, University Science Books, USA, 2006.

36) Hammett, L.P. Physical Organic Chemistry. McGraw-Hill Book Co., New York, 1940.

37) Exner, O. Collection of Czech. Chem. Comm. 1964, 29, 1094.DOI: 10.1135/cccc19641094 
Table 1. Oxidative conversion of aryloximes to arylaldehydes.

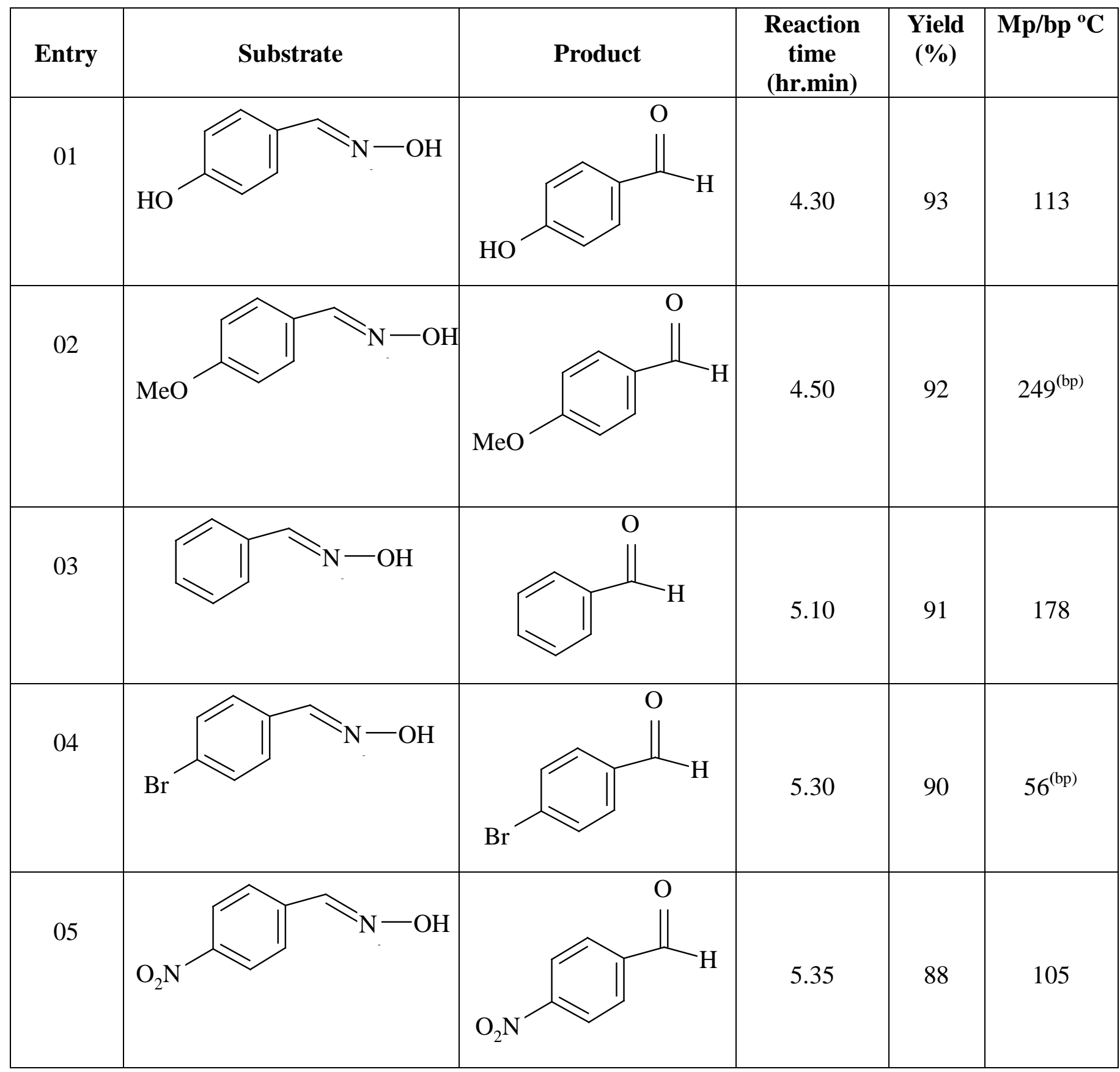


Table 2. Effect of varying $[\mathrm{BAB}]$ and [aryloximes] $]_{\mathrm{o}}$ on the reaction rate at $303 \mathrm{~K}$.

\begin{tabular}{llccccc}
\hline $\begin{array}{l}10^{4}[\mathrm{BAB}] \\
\left(\mathrm{mol} \mathrm{dm}^{-3}\right)\end{array}$ & $\begin{array}{l}10^{3} \text { [aryloximes] } \\
\left(\mathrm{mol} \mathrm{dm}^{-3}\right)\end{array}$ & \multicolumn{1}{l}{$10^{4} \mathrm{~K}^{\prime}\left(\mathrm{s}^{-1}\right)$} \\
\cline { 3 - 7 } & & $-\mathrm{OH}$ & $-\mathrm{OCH}_{3}$ & $-\mathrm{H}$ & $-\mathrm{Br}$ & $-\mathrm{NO}_{2}$ \\
\hline 0.4 & 2.0 & 9.74 & 8.93 & 7.19 & 4.56 & 3.82 \\
0.9 & 2.0 & 9.76 & 8.97 & 7.15 & 4.54 & 3.87 \\
1.8 & 2.0 & 9.75 & 8.95 & 7.18 & 4.52 & 3.85 \\
2.5 & 2.0 & 9.72 & 8.94 & 7.16 & 4.53 & 3.86 \\
3.6 & 2.0 & 9.73 & 8.96 & 7.14 & 4.50 & 3.83 \\
& & & & & & \\
1.8 & 0.5 & 3.73 & 3.24 & 3.01 & 1.84 & 1.59 \\
1.8 & 1.0 & 6.82 & 5.31 & 4.81 & 3.48 & 2.17 \\
1.8 & 2.0 & 9.75 & 8.95 & 7.18 & 4.52 & 3.85 \\
1.8 & 3.0 & 11.8 & 10.3 & 8.89 & 7.80 & 4.74 \\
1.8 & 4.0 & 15.1 & 13.9 & 12.4 & 9.99 & 6.28 \\
\hline
\end{tabular}

$\left[\mathrm{HClO}_{4}\right]=1.6 \times 10^{-4} \mathrm{~mol} \mathrm{dm}^{-3} ;\left[\mathrm{RuCl}_{3}\right]=16.0 \times 10^{-6} \mathrm{~mol} \mathrm{dm}^{-3}$ at $303 \mathrm{~K}$.

Table 3. Effect of varying $\left[\mathrm{HClO}_{4}\right]$ and $\left[\mathrm{RuCl}_{3}\right]$ on the reaction rate at $303 \mathrm{~K}$.

\begin{tabular}{llccccc}
\hline $\begin{array}{l}10^{4}\left[\mathrm{HClO}_{4}\right] \\
\left(\mathrm{mol} \mathrm{dm}^{-3}\right)\end{array}$ & $\begin{array}{l}10^{6}\left[\mathrm{RuCl}_{3}\right] \\
\left(\mathrm{mol} \mathrm{dm}^{-3}\right)\end{array}$ & \multicolumn{1}{l}{$10^{4} k\left(\mathrm{~s}^{-1}\right)$} \\
\cline { 3 - 7 } & & $-\mathrm{OH}$ & $-\mathrm{OCH}_{3}$ & $-\mathrm{H}$ & $-\mathrm{Br}$ & $-\mathrm{NO}_{2}$ \\
\hline 0.4 & 16.0 & 15.1 & 14.2 & 12.5 & 8.84 & 7.43 \\
0.8 & 16.0 & 12.5 & 10.4 & 9.43 & 6.45 & 5.14 \\
1.6 & 16.0 & 9.75 & 8.95 & 7.18 & 4.52 & 3.85 \\
2.4 & 16.0 & 7.95 & 6.14 & 5.45 & 3.60 & 2.80 \\
3.2 & 16.0 & 5.90 & 5.10 & 4.70 & 3.10 & 2.30 \\
& & & & & & \\
16.0 & 4.0 & 5.12 & 4.45 & 2.59 & 2.55 & 1.82 \\
16.0 & 8.0 & 7.43 & 6.72 & 4.85 & 3.63 & 2.94 \\
16.0 & 16.0 & 9.75 & 8.95 & 7.18 & 4.52 & 3.85 \\
16.0 & 24.0 & 12.1 & 11.7 & 11.3 & 5.65 & 4.59 \\
16.0 & 32.0 & 15.5 & 14.4 & 12.6 & 6.40 & 5.20 \\
\hline
\end{tabular}

$[\mathrm{BAB}]=1.8 \times 10^{-4} \mathrm{~mol} \mathrm{dm}^{-3}$; [aryloximes] $=2.0 \times 10^{-3} \mathrm{~mol} \mathrm{dm}^{-3}$ at $303 \mathrm{~K}$. 
Table 4. Effect of varying temperature on the reaction rate and activation parameters for the oxidation of aryloximes by $\mathrm{BAB}$ in presence and absence of $\mathrm{RuCl}_{3}$.

\begin{tabular}{|c|c|c|c|c|c|}
\hline \multirow{2}{*}{$\begin{array}{l}\text { Temperature } \\
(\mathrm{K})\end{array}$} & \multicolumn{4}{|c|}{$\mathrm{k}^{\prime} \times 10^{4} / \mathrm{s}^{-1}$} & \multirow[b]{2}{*}{$-\mathrm{NO}_{2}$} \\
\hline & $-\mathrm{OH}$ & $-\mathrm{OCH}_{3}$ & $-\mathrm{H}$ & $-\mathrm{Br}$ & \\
\hline 293 & $4.42(0.96)$ & $4.14(0.87)$ & $3.62(0.70)$ & $2.25(0.43)$ & $1.49(0.35)$ \\
\hline 298 & $6.92(1.35)$ & $6.12(1.35)$ & $5.41(1.04)$ & $3.28(0.63)$ & $2.47(0.49)$ \\
\hline 303 & $9.75(1.76)$ & $8.95(1.76)$ & 7.18(1.38) & $4.52(0.85)$ & $3.85(0.72)$ \\
\hline 308 & $12.9(2.72)$ & $12.6(2.72)$ & $10.4(2.07)$ & $7.20(1.26)$ & $6.26(1.08)$ \\
\hline 313 & $18.2(3.51)$ & $17.5(3.51)$ & $14.9(2.76)$ & $9.34(1.74)$ & $8.51(1.48)$ \\
\hline$E_{a}\left(\mathrm{~kJ} \mathrm{~mol}^{-1}\right)$ & $35.2(53.6)$ & $42.5(53.6)$ & $46.7(55.9)$ & $53.0(59.7)$ & $56.5(64.2)$ \\
\hline$\Delta H^{\mp}\left(\mathrm{kJ} \mathrm{mol}^{-1}\right)$ & $32.7(51.1)$ & 39.9(51.1) & $44.2(53.4)$ & $50.5(57.1)$ & $53.9(61.6)$ \\
\hline$\Delta G^{\neq}\left(\mathrm{kJ} \mathrm{mol}^{-1}\right)$ & $91.8(96)$ & $92.0(96.0)$ & 92.4(96.6) & 93.6(97.8) & $94.1(97.0)$ \\
\hline$\Delta S^{\neq}\left(\mathrm{JK}^{-1} \mathrm{~mol}^{-1}\right)$ & $-195(-148)$ & $-171(-148)$ & $-159(-142)$ & $-142(-133)$ & $-132(-120)$ \\
\hline
\end{tabular}




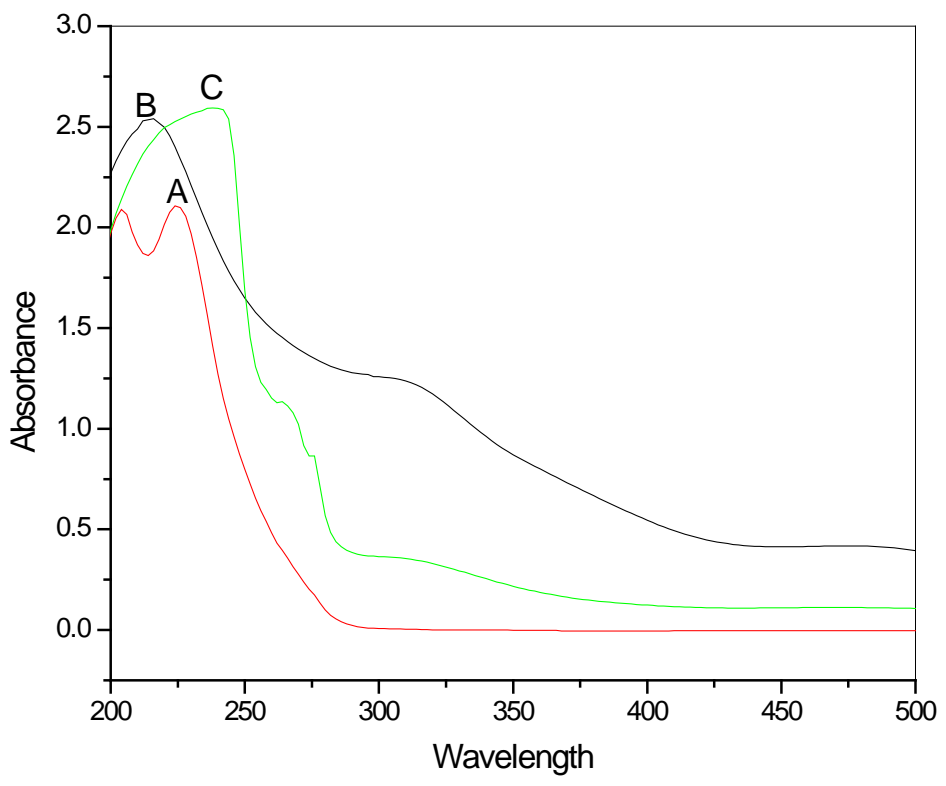

Fig. 1. UV-visible spectra of (A) $\mathrm{RuCl}_{3}$, (B) $\mathrm{BAB}$, (C) Mixture of $\mathrm{RuCl}_{3}$ and $\mathrm{BAB}$ in $\mathrm{HClO}_{4}$ medium. 


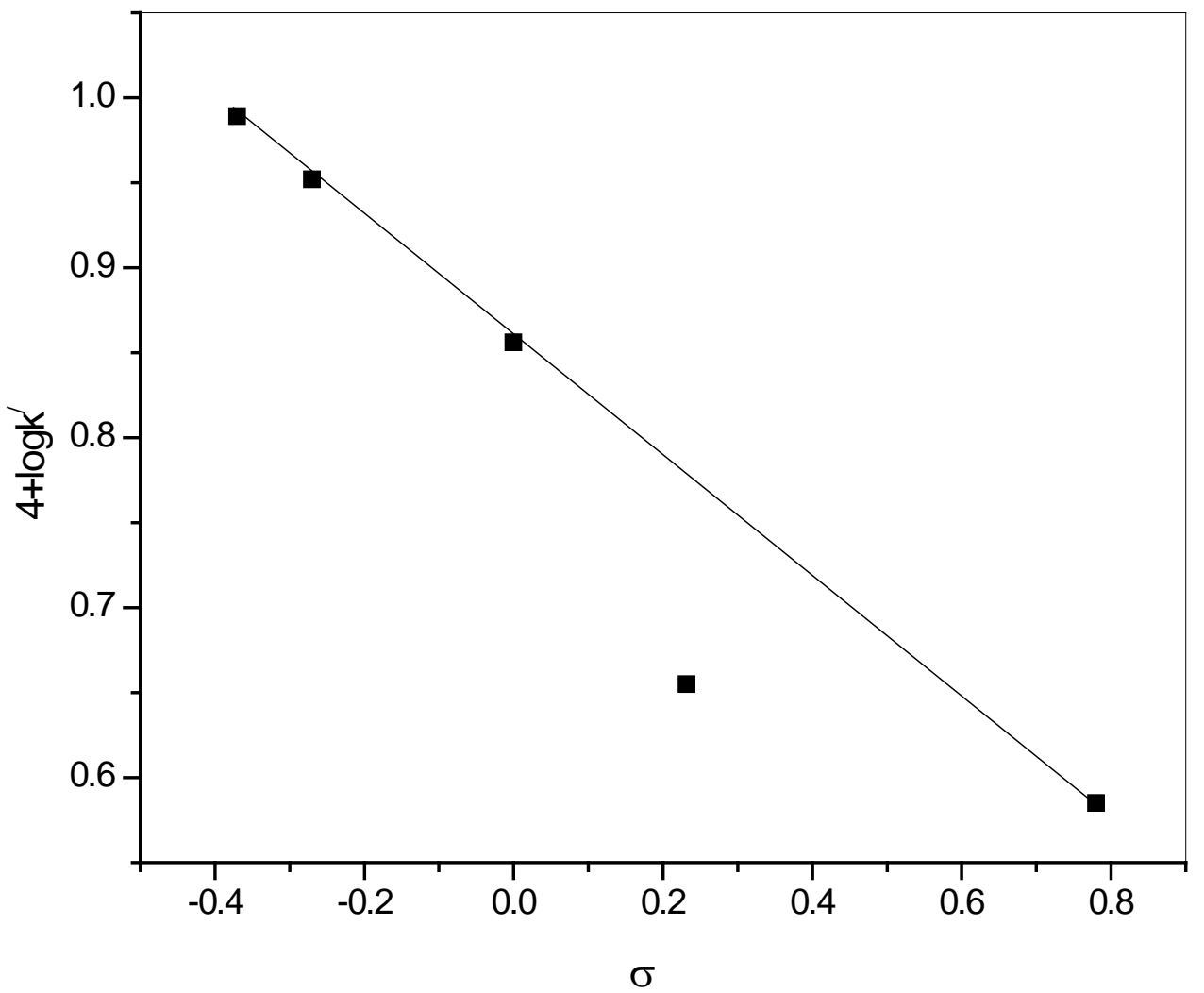

Fig. 2. Hammett plot of $\log \mathrm{k}^{\prime}$ versus $\sigma$. 


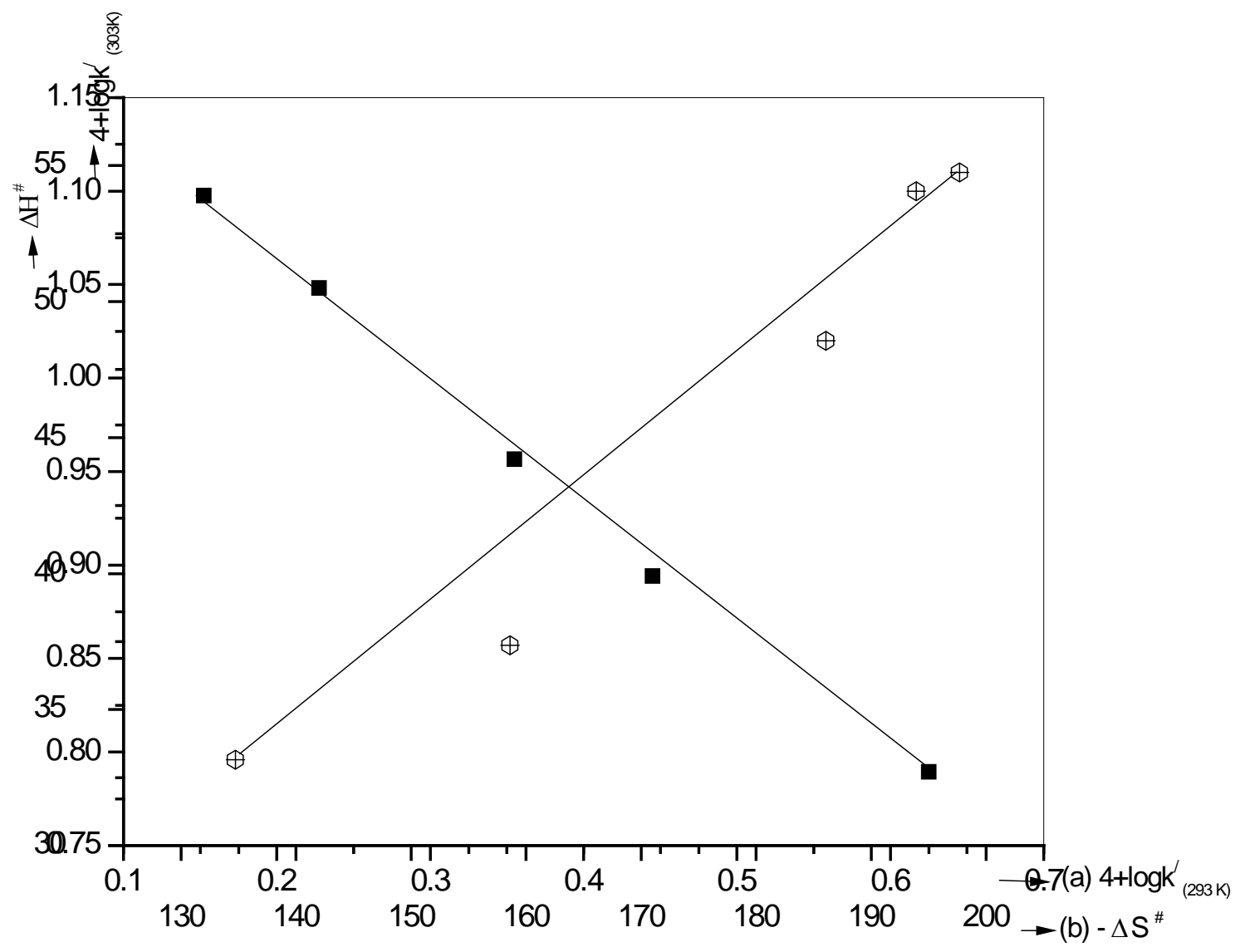

Fig. 3. Isokinetic plots of (a). $\log \mathrm{k}_{(293 \mathrm{~K})}^{\prime}$ versus $\log \mathrm{k}_{(303 \mathrm{~K})}^{\prime}$ (b). $\Delta \mathrm{H}^{\#}$ versus $\Delta \mathrm{S}^{\#}$. 


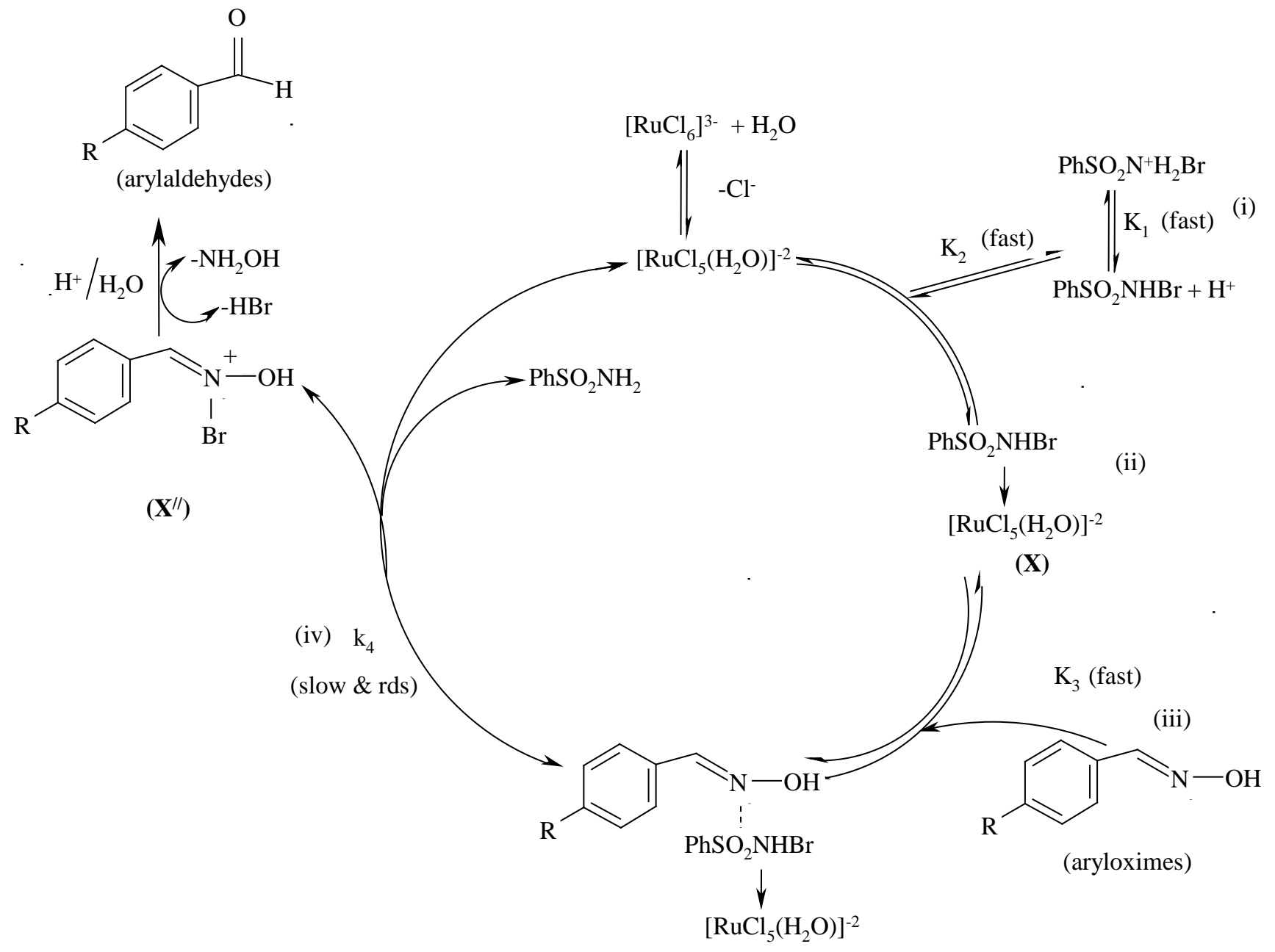

$\left(\mathbf{X}^{\prime}\right)$

Scheme 2. A detailed proposed mechanism for $\mathrm{RuCl}_{3}$ catalyzed oxidative conversion of aryloximes to arylaldehydes with BAB in acid medium. 